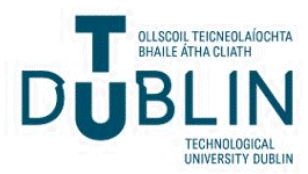

Technological University Dublin

ARROW@TU Dublin

2015-1

\section{A Printed Triangular Monopole with Wideband Circular Polarization}

\author{
Afshin Panahi \\ Technological University Dublin \\ Xiulong Bao \\ Technological University Dublin, xiulong.bao@tudublin.ie \\ Giuseppe Ruvio \\ Technological University Dublin, Giuseppe.Ruvio@tudublin.ie
}

See next page for additional authors

Follow this and additional works at: https://arrow.tudublin.ie/ahfrcart

Part of the Systems and Communications Commons

\section{Recommended Citation}

A. Panahi, X. L. Bao, G. Ruvio, and M. J. Ammann, "A Printed Triangular Monopole with Wideband Circular Polarization", IEEE Transactions on Antennas \& Propagation, vol. 63, issue 1, pp. 415-418, 01/2015 doi:10.1109/TAP.2014.2365828

This Article is brought to you for free and open access by the Antenna \& High Frequency Research Centre at ARROW@TU Dublin. It has been accepted for inclusion in Articles by an authorized administrator of ARROW@TU

Dublin. For more information, please contact

arrow.admin@tudublin.ie, aisling.coyne@tudublin.ie, gerard.connolly@tudublin.ie.

Funder: Irish Higher Education Authority

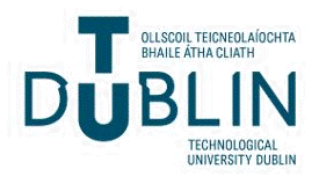




\section{Authors}

Afshin Panahi, Xiulong Bao, Giuseppe Ruvio, and Max Ammann

This article is available at ARROW@TU Dublin: https://arrow.tudublin.ie/ahfrcart/65 


\section{A Printed Triangular Monopole with Wideband Circular Polarization}

\section{A. Panahi, X. L. Bao, G. Ruvio and M. J. Ammann}

Abstract-A printed triangular monopole antenna with wideband circular polarization is presented. The wideband circular polarization is achieved by asymmetrical excitation of a triangular ground plane and planar triangular monopole. The combined radiation provides a wide axial-ratio bandwidth spanning from 1.42 to $2.7 \mathrm{GHz}(62 \%)$. A parametric study of key geometric parameters is given for clear understanding of the radiation mechanism.

\section{INTRODUCTION}

$\mathrm{T}$ HE extensive research activity into wideband and ultra wideband printed linearly-polarized (LP) antennas has recently declined, but is now beginning to focus on circularlypolarized (CP) printed monopole antennas for applications in wireless and satellite communications, radio frequency identification (RFID) and global navigation satellite systems. CP offers advantages over LP such as immunity to Faraday rotation, resilience to polarization mismatch and mitigated multipath losses. In the literature various methods are employed to design CP monopole antennas with both narrow and wide $\mathrm{CP}$ bandwidths.

In [1] the antenna arm and ground plane slot are used to generate dual-band $\mathrm{CP}$ realizing $3 \mathrm{~dB}$ axial ratio (AR) bandwidths of $6 \%$ and $23 \%$ at the lower and upper bands, respectively. An asymmetric monopole is introduced in [2] to generate elliptical polarization (EP). A slit is embedded in the ground plane to provide a $90^{\circ}$ phase difference transforming EP into CP with an AR bandwidth of $31.6 \%$ from 3.2 to 4.4 $\mathrm{GHz}$. Inserting orthogonal slots in a circular planar monopole was used to create orthogonal components where the element lengths were optimized for CP for both GPS and WLAN bands [3] with AR bandwidths of $33.1 \%$ from 1.5 to 2.095 $\mathrm{GHz}$ and $11.83 \%$ from 4.711 to $5.335 \mathrm{GHz}$. In [4] a narrow slit inserted in the ground plane and an asymmetrical dipolelike arm is proposed. By adjusting the arm asymmetry and the length of the ground plane slit, an AR of $38.4 \%$ from 1.81 to $2.67 \mathrm{GHz}$ is accomplished. In [5] $\mathrm{CP}$ is achieved by an asymmetrical truncation of the monopole ground plane, where the AR bandwidth depends on the degree of the ground plane truncation. It yields an AR bandwidth of $36.5 \%$ from 5.91 to

Manuscript received May 13, 2014. This work was part funded by the Irish Higher Education Authority under PRTLI Cycle as part of The Telecommunication Graduate Initiative.

A. Panahi, X. L. Bao, G. Ruvio and M. J. Ammann are with the Antenna High Frequency Research Centre, Dublin Institute of Technology, Dublin 8, Ireland (e-mail: c07801441@mydit.ie; xbao@dit.ie; Giuseppe.ruvio@dit.ie; max.ammann@dit.ie).

Color versions of one or more of the figures in this paper are available online at http://ieeexplore.ieee.org.
8.55 GHz. In [6] a rectangular printed monopole is fed asymmetrically so that the two orthogonal sides of the rectangle produce $\mathrm{CP}$ where the modified ground plane helps to achieve a wide AR bandwidth of $60 \%$ from 1.42 to 2.65 GHz. A monopole antenna with two equal arms is reported in [7] where the ground plane structure produces the $90^{\circ}$ phase delay between the two arms. The AR bandwidth is $16 \%$ from 1.38 to $1.64 \mathrm{GHz}$. In [8] coupled inverted L and $\mathrm{U}$ shape strips combined with a slotted ground plane are used for generating $\mathrm{CP}$ with an $\mathrm{AR}$ bandwidth about $60 \%$ from 2 to 3.8 GHz. In [9] a slit in the ground plane and an added stub disturb the ground plane current, forming one of the two required orthogonal components along with the monopole for the CP performance giving an AR bandwidth reaching $44.9 \%$ from 4.58 to $7.23 \mathrm{GHz}$. A moon-shaped radiator is used in [10] to achieve a wideband $\mathrm{CP}$ performance with $\mathrm{AR}<3 \mathrm{~dB}$ from 2.28 to $3.76 \mathrm{GHz}$. A monopole antenna comprising an annular-ring connected to a square loop as a radiator and a slotted ground plane is reported in [11] to have a dual-band CP with AR bandwidth of $12.5 \%$ from 3.3 to $3.74 \mathrm{GHz}$ and $3.8 \%$ from 5.64 to $5.86 \mathrm{GHz}$.

Most of the $\mathrm{CP}$ monopole antennas in the literature have relatively complex geometries with ground plane slots and stubs employed in the CP generation. In contrast, a simpler structure is proposed which achieves an AR bandwidth of $62 \%(1.42 \mathrm{GHz}$ to $2.7 \mathrm{GHz})$ which is wider than [1-11]. The antenna has no slits or slots in the ground plane, thus mitigating the constraints of populating the ground plane with components or modules.

An asymmetrically excited right-angle isosceles triangular ground plane and a right-angle isosceles monopole are employed to generate CP over a wide bandwidth. The ground plane hypotenuse is chosen to be approx. $\lambda_{0} / 2$ at the lowest $\mathrm{CP}$ frequency. Compared to the proposed triangular ground plane, an asymmetrically-fed rectangular layout with the same side dimension would have twice the area, yielding a squinted (offbroadside) radiation pattern with reduced beamwidth and narrower AR bandwidth. Furthermore the triangular fed element improves the stability of the radiation pattern with change of frequency.

A parametric study was conducted to provide better understanding of the relationship between the antenna dimensions and the AR bandwidth. The sensitivity of the AR to the ground plane size, the radiating triangular arm size, the monopole feed position on the ground plane and the gap between the ground plane and the antenna arm are investigated. As the ground plane is a critical part of a $\mathrm{CP}$ monopole radiating system which is often taken for granted in the literature, the mechanism for generating $\mathrm{CP}$ from a triangular ground plane is described in section II. For simplicity a simple monopole strip is initially considered.

\section{CP MECHANISM OF STRIP MONOPOLE ON A TRIANGULAR GROUND PLANE}

The geometry and dimensions of the strip monopole antenna are shown in Fig. 1. It is fed by a $50 \Omega$ microstrip line and printed on double-sided FR-4 with $\varepsilon_{\mathrm{r}}=4.3, \tan \delta=0.025$ and a thickness of $1.52 \mathrm{~mm}$. The ground plane is a right- 
angled isosceles triangular-shape with $L_{1}=L_{2}=79.2 \mathrm{~mm}$ and $L_{3}=112 \mathrm{~mm}$ and the monopole strip width is $3 \mathrm{~mm}$.

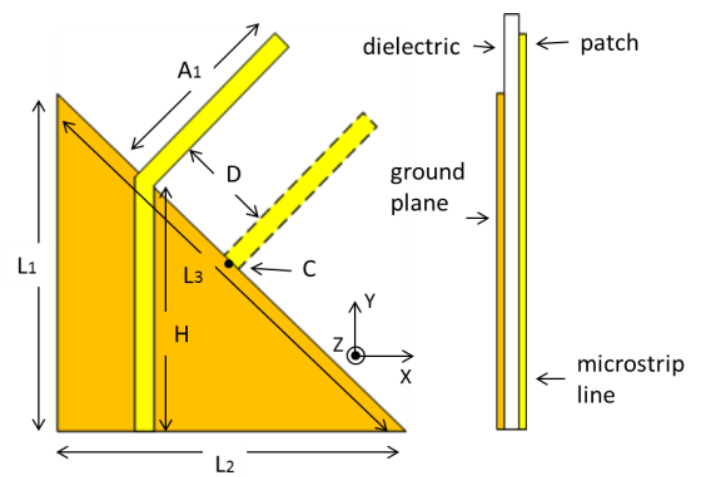

Fig. 1. Strip monopole geometry, $A_{1}=36.5 \mathrm{~mm}, L_{l}=L_{2}=79.2 \mathrm{~mm}, L_{3}=112 \mathrm{~mm}$ and $H=54.35 \mathrm{~mm}$

By asymmetrically feeding the strip with respect to the ground plane hypotenuse, two orthogonal electric field vectors are excited with equal amplitude and their phase-time difference depends on the degree of the asymmetry. The ground plane hypotenuse is chosen to be approx. $\lambda_{0} / 2$ at the lowest $\mathrm{CP}$ frequency, which is $1.35 \mathrm{GHz}$. The phase difference between the two vectors depends on the monopole feed position on the hypotenuse. When the arm is located in the center of the hypotenuse, the induced currents on each side of the hypotenuse are oppositely directed and in-phase, therefore they cancel, resulting in linearly-polarized radiation from the strip monopole arm. When the antenna arm is moved away from the center, the currents flowing on each side of the hypotenuse are unequal and phase-shifted, realizing elliptical or circular polarization. The phase difference for $\mathrm{CP}$ is tuned when the arm is moved away by a distance of $\lambda_{0} / 8$ from the hypotenuse center in either direction. The direction that the arm is moved determines the sense of $\mathrm{CP}$ i.e. right-hand $\mathrm{CP}$ (RHCP) or left-hand CP (LHCP) in the $+\mathrm{Z}$ direction.

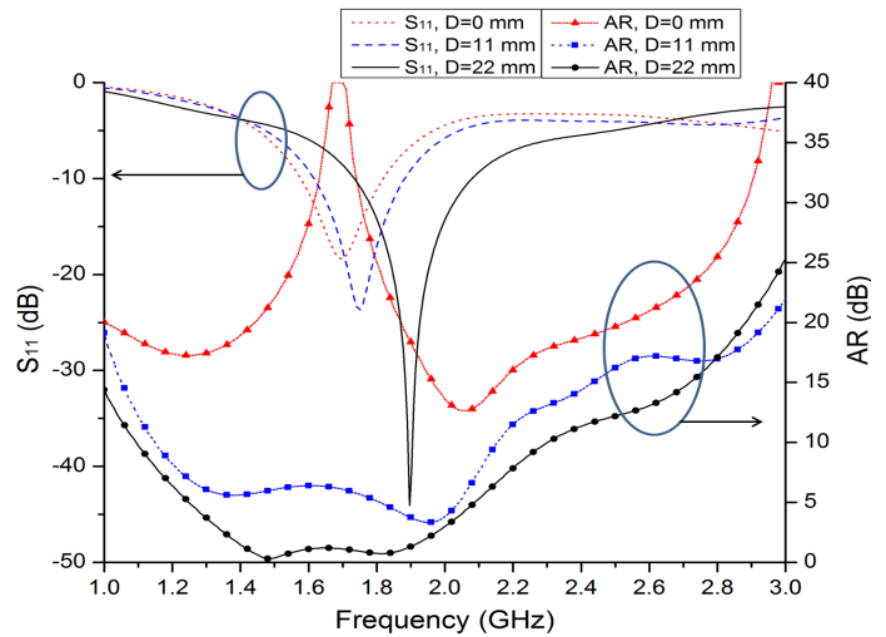

Fig. 2. AR and $S_{11}$ dependence on the monopole feed position on the hypotenuse $\mathrm{L}_{3}, \mathrm{D}$ is the distance from center point $\mathrm{C}$
Fig. 2 demonstrates the AR dependence on the monopole location on the hypotenuse where $D$ is the distance from the hypotenuse center point $\mathrm{C}$. Furthermore, by changing the ground plane size with the arm location fixed, the AR band can be tuned up and down by decreasing and increasing the ground plane size as shown in Fig. 3. The length of the strip $A_{l}$ is chosen so that the antenna is matched at the center frequency of $1.7 \mathrm{GHz}$. In general the length of the monopole depends on the ground plane size and the monopole feed location on the ground plane. By moving the arm away from the hypotenuse center to tune the phase difference for $\mathrm{CP}$, the antenna resonant frequency shifts upwards. The $\mathrm{S}_{11}$ dependence on the monopole feed location on the hypotenuse is shown in Fig. 2. To maintain the resonance at $1.7 \mathrm{GHz}$, the strip length $A_{l}$ is increased. Small variations in the monopole length have little effect on the AR bandwidth.

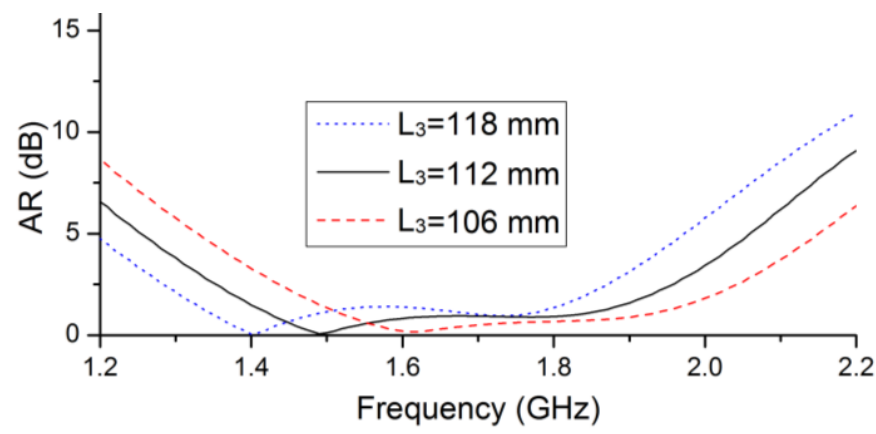

Fig. 3. AR dependence on the ground plane size

The surface current distribution is shown in Fig. 4. The surface current vectors are shown at $1.575 \mathrm{GHz}$ as the phase changes from $0^{\circ}$ to $270^{\circ}$. The dominant radiating currents are in the $-\mathrm{X},-\mathrm{Y},+\mathrm{X}$ and $+\mathrm{Y}$ directions for the $0^{\circ}, 90^{\circ}, 180^{\circ}$ and $270^{\circ}$ phases, respectively, and generate RHCP in the $+Z$ direction. CP is generated by the currents on the monopole arm and the ground plane hypotenuse.

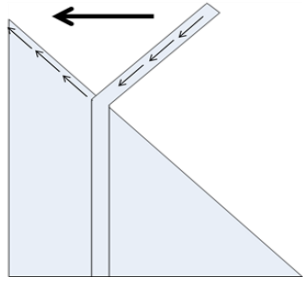

(a)

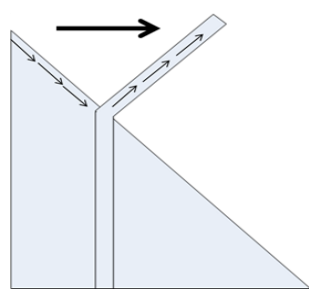

(c)

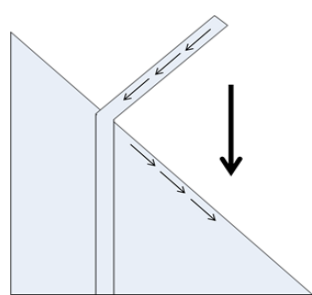

(b)

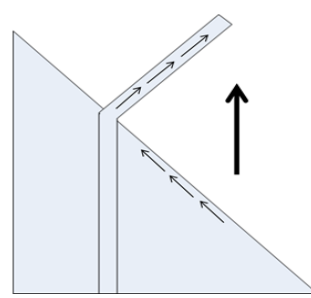

(d)
Fig. 4. Surface current at $1.575 \mathrm{GHz}$ for (a) $0^{\circ}$, (b) $90^{\circ}$, (c) $180^{\circ}$ and (d) $270^{\circ}$ 


\section{DESIGN OF THE TRIANGULAR MONOPOLE ANTENNA}

The strip monopole has a narrow $S_{11}$ bandwidth which does not fully cover the CP bandwidth. To further enhance the impedance and the AR bandwidth, the monopole strip is replaced by a right-angled isosceles triangle shown in Fig. 5, keeping the same ground plane size. This introduces an additional CP mode due to the extra edges of the triangle. The triangle size is optimized to achieve $\mathrm{CP}$ in the desired frequency range. By increasing or decreasing the triangle size, the additional $\mathrm{CP}$ band can be tuned up or downwards in frequency. The size is chosen so that the first and second $\mathrm{CP}$ bands overlap to provide a continuous band covering 1.42 $\mathrm{GHz}$ to $2.52 \mathrm{GHz}$. By increasing the ground plane size or reducing the monopole hypotenuse size or both, the $\mathrm{CP}$ bandwidth will split into two bands. Fig. 6 exhibits the AR bandwidth dependence on the triangular monopole size.

As with all planar monopoles, the gap $g$, between the ground plane and the monopole is a key parameter, affecting mainly the $S_{11}$ as shown in Fig. 7. The AR bandwidth is also influenced by the gap as shown in Fig. 8. The AR is more sensitive to the feed gap at the higher frequencies due to coupling effects between the monopole and the ground plane hypotenuse.

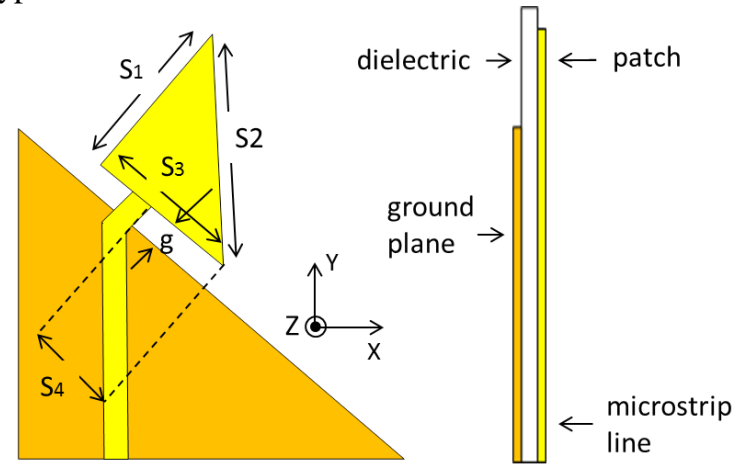

Fig. 5. Proposed antenna geometry with $S_{1}=S_{3}=35.56 \mathrm{~mm}, S_{2}=50.3 \mathrm{~mm}$, $S_{4}=22 \mathrm{~mm}$ and $g=4.5 \mathrm{~mm}$

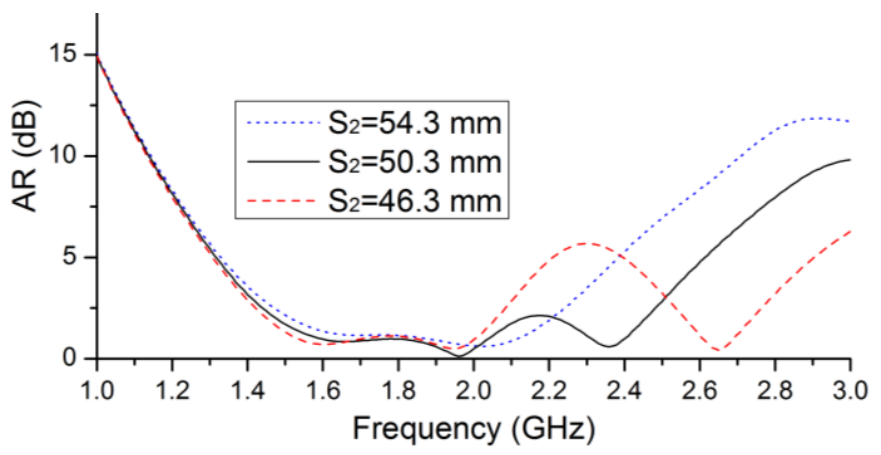

Fig. 6. AR bandwidth dependence on the monopole triangle size

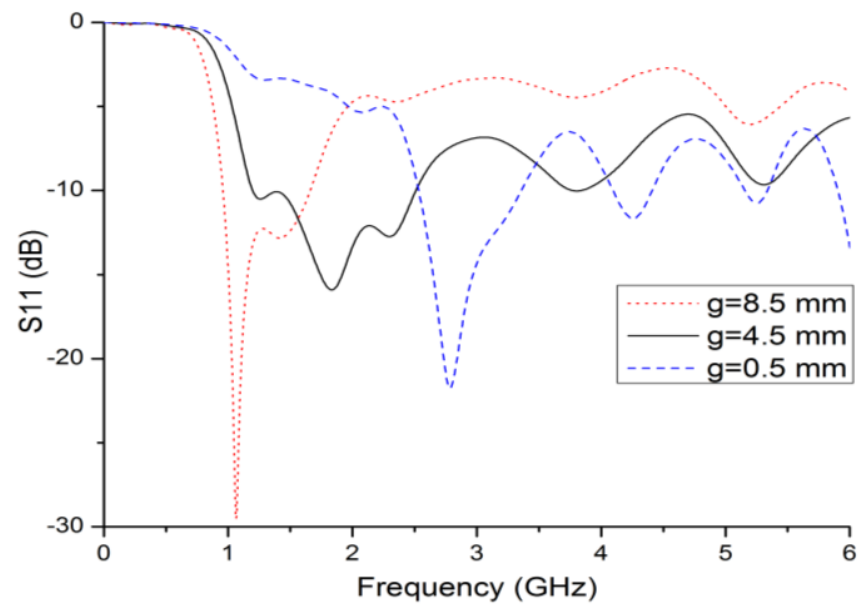

Fig. 7. $\mathrm{S}_{11}$ dependence on gap variation for $g=8.5,4.5$ and $0.5 \mathrm{~mm}$

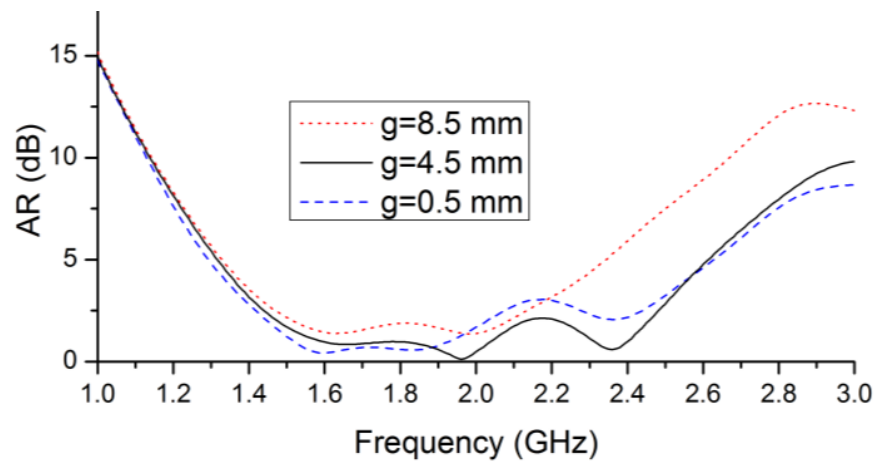

Fig. 8. AR dependence on gap variation for $g=8.5,4.5$ and $0.5 \mathrm{~mm}$

The surface current distribution at $2.45 \mathrm{GHz}$ as the phase changes from $0^{\circ}$ to $270^{\circ}$ is shown in Fig. 9. The dominant radiating currents are in the $-\mathrm{X},-\mathrm{Y},+\mathrm{X}$ and $+\mathrm{Y}$ directions for the $0^{\circ}, 90^{\circ}, 180^{\circ}$ and $270^{\circ}$ phases, respectively, and generate $\mathrm{RHCP}$ in the $+\mathrm{Z}$ direction. $\mathrm{CP}$ is generated by the currents on two sides of the triangular monopole and the ground plane hypotenuse.

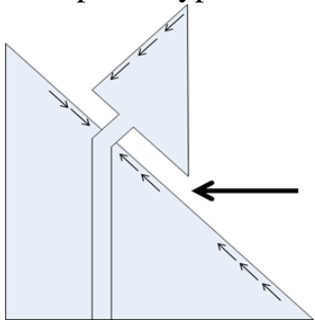

(a)

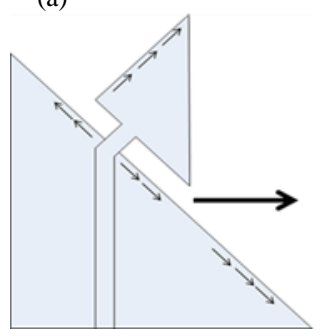

(c)

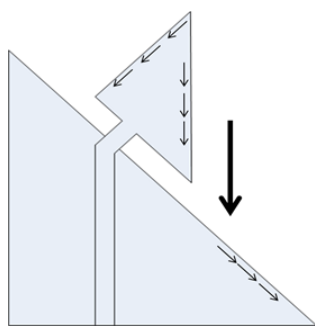

(b)

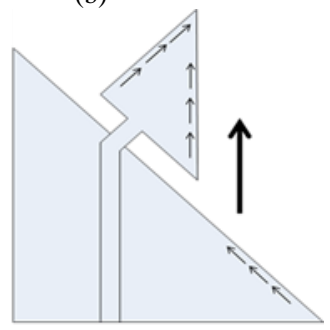

(d)
Fig. 9. Surface current distribution at $2.45 \mathrm{GHz}$ for (a) $0^{\circ}$, (b) $90^{\circ}$, (c) $180^{\circ}$ and (d) $270^{\circ}$. 


\section{SimUlation AND MEASUREMENT RESUltS OF THE PROPOSED ANTENNA (ANTENNA 2)}

A comparison of the measured and simulated $S_{11}$ and $A R$ are shown in Fig. 10. The measured $S_{11}$ fractional bandwidth is $60 \%$ with respect to the center frequency of $2.0 \mathrm{GHz}$, covering a frequency range from 1.4 to $2.6 \mathrm{GHz}$. The measured and simulated AR bandwidth were found to be approximately $62.5 \%(1.42-2.7 \mathrm{GHz})$ and $56 \%(1.42-2.52$ $\mathrm{GHz}$ ) respectively. The small discrepancies are attributed to fabrication tolerances and chamber mounting arrangements. The normalized simulated and the measured radiation patterns

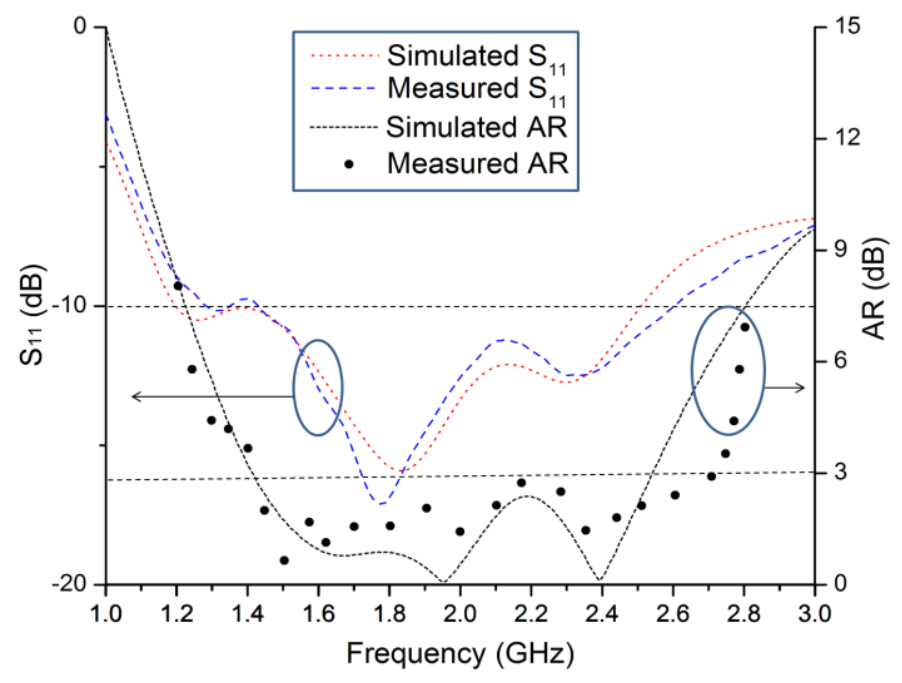

Fig. 10. Simulated and measured $S_{11}$ and $A R$

are shown in Figs. 11 and 12. There is a good agreement between the simulated and measured patterns in the $\mathrm{ZX}$ and $\mathrm{ZY}$ planes. The peak realized gain was $1.7 \mathrm{dBic}$ and 2.22 dBic and the total efficiency was $90 \%$ and $85 \%$ at 1.575 and $2.45 \mathrm{GHz}$, respectively. The efficiency varies across the $3 \mathrm{~dB}$ AR bandwidth from $92 \%$ to $74 \%$. The patterns illustrate a broad 3-dB XZ plane beamwidth of $90^{\circ}$ and $80^{\circ}$ at $1.575 \mathrm{GHz}$ and $2.45 \mathrm{GHz}$, respectively, which is stable across the band.
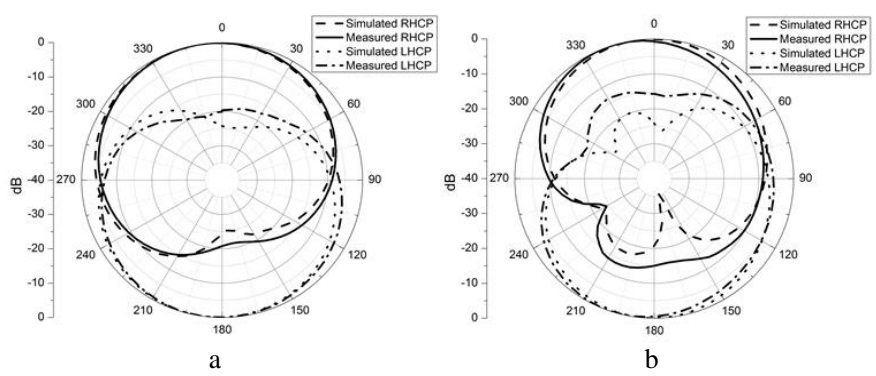

Fig. 11. Normalized measured and simulated radiation patterns in the $\mathrm{XZ}$ (a) and $\mathrm{YZ}$ (b) planes for $1.575 \mathrm{GHz}$
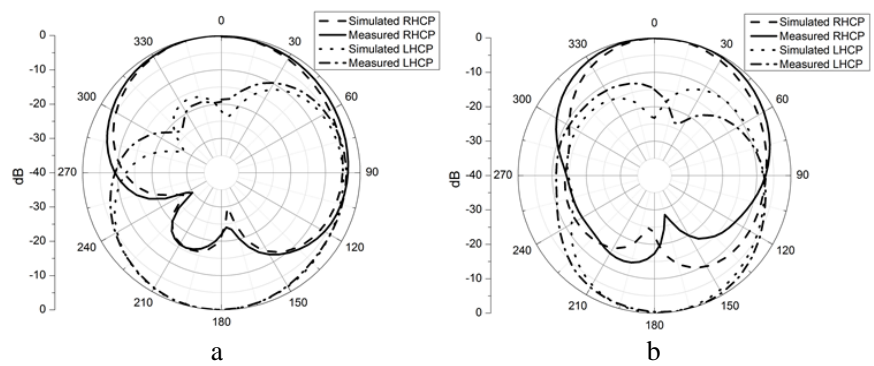

Fig. 12. Normalized measured and simulated radiation patterns in the $\mathrm{XZ}$ (a) and $\mathrm{YZ}$ (b) planes for $2.45 \mathrm{GHz}$

\section{CONCLUSION}

A simple low-cost, CP planar monopole antenna is reported. The combination of a triangular ground plane and asymmetrically-fed triangular element provides two overlapping $\mathrm{CP}$ modes which realize a large AR bandwidth. The triangular ground plane mitigates squint in the radiation pattern due to the feed asymmetry and contributes to maintaining a wide beamwidth across the wideband wellmatched AR bandwidth, which is $62 \%$ from 1.42 to $2.7 \mathrm{GHz}$.

\section{REFERENCES}

[1] E.F. Jou, J.W. Wu and C.J. Wang,"Novel broadband monopole Antennas With Dual-Band Circular Polarization", IEEE Transactions Antennas and Propagation, AP57, (4), pp: 1027-1034, 2009

[2] J.W.WU, J.Y. Ke, C.F.Jou, C.J.Wang,"Microstrip-fed broadband Circularly-polarized monopole antenna", IET Microwaves, Antenna \& Propagation, 4, (4), pp.518-525, 2010

[3] S.A.Rezaeieh,"Dual band dual sense circularly polarised monopole antenna for GPS and WLAN applications", Electronics Letters, 47, pp: 1212-1214, Oct.2011

[4] X.L.Bao and M.J.Ammann,"Printed circularly polarised antenna with ultra-wide axial-ratio bandwidth", IET Microwaves, Antennas \& Propagation, 5, (9), pp: 1089-1096, 2011

[5] B.Chen, Y.-C.Jiao, F.-C.Ren and L.Zhang,"Broadband Monopole Antenna With Wideband Circular Polarization", Progress In Electromagnetics Research Letters, 32, pp: 19-28, 2012

[6] T.Fujimoto and K.Jono,"Wideband Printed Rectangular Monopole Antenna for Circularly Polarization", IET Microwaves, Antennas \& Propagation, 8, (9), pp: 649-656, 2014

[7] C.N.Chiu and C.C.Yang,"A New Board-Integrated Single Microstriped Circularly Polarized Antenna for Global Positioning Satellite Receivers",Journal of Electromagnetic Waves and Applications, 24, (7), pp: 903-909, 2010

[8] T.N.Chang and J.M.Lin," Wideband circularly antenna on slot-loaded ground plane",Electronics Letters, 48, (14), pp: 818-819, 2012

[9] L.Zhang, Y.C.Jiao, Y.Ding, B.Chen and Z.B.Weng," CPW-Fed Broadband Cicularly Polarized Planar Monopole Antenna With Improved Ground-Plane Structure “, IEEE Transactions on Antennas and propagation, AP-61, (9), pp: 4824-4828, 2013

[10] B.Hu, Nasimuddin and Z Shen,"Moon-Shaped Printed Monopole Antenna for Wideband Circularly Polarized Radiation",IEEE-APS Topical conference on Antennas and Propagation in Wireless Communications (APWC), pp: 825-827, 2013

[11] K. Ding, T. Yu, D.-X. Qu, and C. Peng, "A novel loop-like monopole antenna with dual-band circular polarization,"Progress In Electromagnetics Research C, 45, 179-190, 2013. 